\title{
Intellectual Capital as an Indicator of a Sustainable Development
}

\author{
Pavel Makarov \\ Faculty of Economics, Vladimir State University \\ Russian Federation, Vladimirskaya obl. \\ Vladimir, mkr. Kommunar, Zelenaya, d. 60, kv. 130 \\ Tel: 7-4922-32-85-20 E-mail: makarovpu@ya.ru
}

\begin{abstract}
The purposes of this article are to consider the role of intellectual capital concept in context of sustainability and to try to use it for an estimation of sustainable development progress. These aims are based on suggestion that there is the correlation between success of sustainable development in region and level of regional intellectual capital. Proceeding from this, it is possible to generate the intellectual capital model related to sustainability problematics. Such model can be used to estimate successes of sustainable development itself and (on conceptual level) become the basis for further research on this direction.
\end{abstract}

Keywords: Regional intellectual capital, Sustainable development

\section{Specificity of sustainable development estimation}

It is not easy to realize principles of sustainable development in practice. There are different obstacles, such as difficulty of economic development coordination with ideas of sustainability and indifference of society to the given problematic. Besides these uncolved contradictions it is necessary to note such problem as an absence of accurate criteria for an estimation of sustainable development successes in a concrete region. Sustainable development now is not only an ecologically-based paradigm - it concerned with economic and social aspects of human development and claims for a role of ideology for post-industrial society.

Consideration of transition to a sustainable development allows us to speak about it as a recurrent process. At a certain stage of development is formed two key conditions: achievement of high social and economic level and increase in potential costs from instability. These factors cause the perception of sustainable development ecological aspect: life-quality improvement contributes to attention on environmental problems, and then reorganisation of economy starts to influence living conditions. Realisation of other aspects leads to formation of social and economic conditions on the one hand being the purpose, and on the other - necessary for the further development in this direction (fig. 1).

Figure. 1.

A society with weak economy and a low standard of living is forced to live in contradiction with ideas of stability: absence of technologies brings to expansion of inefficient production, and there is no point in their modernisation - additional expenditures are unjustified in the conditions of unstable economy. Thus people are enforced to think about tomorrow for them personally instead of "global future".

Individuals can care of reasonable resource consuming and living conditions of future generations only after achievement of a certain social and economic level of development. Hence, really functioning mechanisms of transition to a sustainable development are possible only with increase of social-economic level of life.

However, indicators characterising these problematics are diverse and difficult for interpretation. Achievement of development sustainability means transformation to post-industrial society and development of human capital and innovative potential as source of economic competitiveness. Proceeding from it we can assume that development of intellectual capital promotes regions transition to a sustainable development, and for an estimation of its success it is possible to use the conception of the intellectual capital.

\section{Structure of the intellectual capital}

One of the modern economy features - strengthening of the non-material factors influence, at the same time they are excepted from traditional vision on organization. They find the reflexion in various concepts: creative thinking in management, core competences and "competing for the future", etc. These factors form the sphere of the intellectual capital.

There are different intellectual capital definitions; most of them describe it as an integrated term for intangible factors of organisation work. For instance, A. Brooking (an author of popular book on this problematics) defines intellectual capital as the "combined intangible assets which enable the company to function" (Brooking, 1996). Rather wide determination gives N. Bontis - "the hidden values of individuals, enterprises, institutions, communities and regions that are the current and potential sources for wealth creation. These hidden values are the roots for nourishment and the cultivation of future wellbeing" (Bontis, 2004).

The intellectual capital also can be examined as a combination of human capital concept and knowledge management ideas: it integrates together knowledge and their parent - individual. Such vision underlies the intellectual capital model presented by Edvinsson and Malone (1997), according it the intellectual capital is 
subdivided into the human capital ("the capabilities of the company's employees necessary to provide solutions to customers, to innovate and to renew") and structural capital ("includes the quality and reach of information technology systems, company images, databases, organizational concept and documentation"), and latter includes the relational and organizational capital as specificity of external and internal interaction of the company employees (fig. 2). The organizational capital also is divided into the process and innovative capital. This model became one most frequently used in theory and practice of intellectual capital.

Figure 2.

Generally, there is more similarity than distinctions between current intellectual capital models. Most authors declare such elements as named above, though can use other terms as well. The intellectual capital step by step becomes a part of management vision, so "hidden values" are frequently get uncovered. At the same time, the national (or regional) intellectual capital concept is in early level of study. There are different methods of regional intellectual capital measurement, among them the most well-know are National Intellectual Capital Index (NICI) (Bontis, 2004), based on Edvinsson's model, and the Intellectual Capital Monitor (Andriessen, Stam, 2004) which integrates classic intellectual capital model and "The Intangible Assets Monitor" by Sveiby (1997). Those models describe "macro-level" intellectual capital not only as economy-related concept but also as a life-quality factor. Furthermore, there are no consistent results on intellectual capital economic role: some measurement show that it acts as an economic driver, but the other has not prove this suggestion (Ståhle, 2008). So it seems more useful to consider regional intellectual capital wider and uncover its potential as development factor: using the intellectual capital concept, we can try to allocate the indicators which can correctly reflect success of social and economic sustainable development aspects in a region. It is necessary not only to characterise a current condition, but also to consider possibility of the further progress, namely: is the region population ready to live and work in a sustainable economy? Is its industry ready to it?

At this time all existent models ordered to measure intellectual capital itself - not in context of other problematics. Estimation of the intellectual capital elements listed above tells nothing without interpretation. Moreover, the conception of intellectual capital is related with the social-economy problems not only in sustainability aspects, and it complicates direct interpreting of measure results. For this reasons, there is no necessity to use regular intellectual capital models and it is preferably to generate model related with research aims (fig. 3); otherwise inconveniently ensure allocation of intellectual capital elements corresponding to our area of interests.

Figure. 3 .

Thus, we can compare the research objectives (revealing of current achievements in social and economic sphere of a sustainable development and an estimation of its further perspectives) with elements of the intellectual capital which can be the indicator for several purposes.

Proceeding from the content of intellectual capital elements can be assumed that sustainable development social aspect and human potential of region (in the context of the further development) correlates with human and relational capital level, and economic aspect (also readiness of economy to work in the setting of sustainable development) - with a structural capital, in particular: innovation capital elements characterise an economic development level, and the organizational capital - institutional bases of transition to a sustainable development.

Figure. 4.

Relational capital also can mean the "soft power" of sustainable development — how strong "sustainable" region image influences on movement to sustainable development in the world but this aspect now is out of consideration.

\section{Definition of sustainable development progress model}

The main element of the Intellectual capital is the human capital. And it is obvious that the characteristic of a sustainable development social aspects expediently to state through the human capital estimation. The most wide-spread indicator of the human capital (though in this sense it is not considered) - a Human Development Index (HDI), reflecting life-quality as set of factors: longevity, literacy, economic well-being. However, it does not applicable for our research as it is termed for other purposes. The estimation of a human capital should reflect first of all the ability to move to a sustainable development. Nevertheless, separately it is necessary to consider quality of life to add an evaluation of a sustainable development social aspect success. So, one index should characterise satisfaction of "base" requirements of individuals and society as a whole, and the other - its social development.

The first index should describe the standard of living which, apparently from the considered example, it is possible to characterise through level of public health services and incomes level (fig. 5). Public health level we can try to describe by disease rate as integral indicator. But GDP which usually applies to the characteristic of economic development does not always reflect the real distribution of incomes correctly and is often criticised by economists. For ex., J. Stiglitz, the Nobel laureate in economics, has expressed opinion that the system of account of GDP is unsuccessful, since costs efficiency can be different, for example, the USA spend huge means for public health services, but thus its indicators are much lower, than in the majority of the European countries. Similarly in the USA the highest percent of prisoners among all developed countries, and is a sign of wrong society organisation 
while penitentiary service expenditures increase GDP (2009). So it seems more useful to estimate level of incomes by share of the population with incomes below subsistence.

Besides these two factors, it is necessary to evaluate threats to well-being of the individual, generated by society criminal level.

Index can be made by analogy with HDI, but with the inverse relationship of indicators: "best" significance of index equals to 0 (no crimes and a disease case on 1000 persons and $0 \%$ of people with incomes below a subsistence) and "worst", accordingly, to 1.

$$
L L I=\sum a_{j} \frac{X_{\max }-X_{j}}{X_{\max }-X_{\min }}
$$

LLI — life-level index; $\mathrm{Xj}$ — actual value of the indicator describing $\mathrm{j}$-th element; Xmin и Xmax — min and $\max$ value of the indicator describing $\mathrm{j}$-th element; aj — weighting.

Figure. 5.

The second index should characterise the "productive" part of the Human capital and uncover its functional qualities: higher education level (characterises availability of theoretical knowledge), level of patent applications as the ability to create knowledge and level of high-tech export as the characteristic of intellectual sphere international competitiveness.

$$
I P I=\sum a_{j} \frac{X_{j}-X_{\min }}{X_{\max }-X_{\min }}
$$

IPI — intellectual potential index; $\mathrm{Xj}$ — actual value of the indicator describing $\mathrm{j}$-th element; Xmin и Xmax min and max value of the indicator describing $\mathrm{j}$-th element; aj - weighting.

Figure. 6.

Sustainable development economic aspect is presumably correlated with readiness of economy to work in new conditions. Assuming innovative potential as basis of post-industrial economy competitiveness we will consider innovation capital of a region.

First of all it is necessary to see what kinds of changes are made: whether is a source of innovations: import of the equipment and licenses, or own region enterprises researches? It is important to have rational combination of methods: usage of only own scientific potential is more preferable but irrational as well as a complete dependence from external intellectual assets. Thus, an offered index of structure of innovation has no outlined gradation (at least until their expediency will not be empirically confirmed) and supposedly should be in limits $0,7-1,3$; greater or smaller significance testifies to prevalence of one innovations method.

$$
I_{I S}=\frac{S_{c}}{S_{n}}
$$

$\mathrm{Sc}$ - number of the enterprises carrying out innovations by own research, or research involved in region; $\mathrm{Sn}$ - number of the enterprises carrying out innovations by import of technologies and equipment.

The structure of acquired innovations should be evaluated in accordance to long-term efficiency, for this purpose is possible to apply an index of intellectual activity of the organizations. Long-term stability and acquisition of technology which can be improved by own strength are more reliably than purchase of the new equipment.

$$
I_{I A}=\frac{N_{a}}{N_{p}}
$$

$\mathrm{Na}$ - number of the enterprises acquiring new technologies in the form of intellectual assets (the licences, the industrial designs, know-how; software); $\mathrm{Np}$ - number of the enterprises acquiring new technologies by purchase of the equipment.

The organizational capital can be considered as orientation of regional institutes to sustainable development achievement. Its estimation, accordingly, will base on the official documentation content-analysis about reflection of the sustainable development problems. The further actions, in this case, are advanced by received information character as the wide range of situations is possible in region development plans: from availability of the generated programs on movement to a sustainable development, containing the efficiency criteria, to absence of any mention on the given concept. Depth of the strategy approach to the given subjects can be described by following factors:

- a sustainable development mention as the region purposes;

- disclosing of the given concept within the limits of strategy;

- availability of the movement to a sustainable development success control;

- the description of the basic problems at movement to a sustainable development;

- the description of a sustainable development top directions. 
Thus, generated model uncovers the problems of movement to a sustainable development (fig. 7), it is enough "compact" and does not assume difficult system of indicators, so given model is convenient in use. The main suggestion on which it is based also gives the new point of view on sustainable development estimation and characterises intellectual capital as a sustainable development indicator.

Figure. 7.

This model does not claim for exhaustive disclosing of this point in question, and works on model perfection are possible. For example, it needs to be tested in practice (and one more problem here - how to indicate the results reliability?). Also deserves attention an interpretation of relational capital as "soft power" of region and consideration of its estimation methods (which presumably must base on some kind of content analysis, because this problem is hardly gives to numerical description).

The main limitation of the model is in low evidence of intellectual capital reflection to sustainability context: it may be not complete or have hidden contradictions. This limitation concerned with problems of regional intellectual capital concept - there is not enough knowledge on this problematic today. At this time, accordingly to current directions on regional capital research, it seems unlikely if further development of the intellectual capital concept will show up serious objections to suggestions made in this paper.

\section{References}

Andriessen, D., Stam, C. (2004). The Intellectual Capital of the European Union /Measuring the Lisbon Agenda [online]. Available: http://www.intellectualcapital.nl/artikelen/ICofEU 2004.pdf

Bontis N. (2004). National Intellectual Capital Index. A United nations initiative for the Arab region, Journal of Intellectual Capital, 1, 13-39.

Brooking, A. (1996). Intellectual Capital: Core Assets for the Third Millennium Enterprise, Thomson Business Press, London, United Kingdom.

Edvinsson, L., Malone, M. (1997). Intellectual Capital: Realising Your Company's True Value by Finding its Hidden Brainpower, Harper Collins, New York.

Ståhle, P. (2008). National Intellectual Capital as an Economic Driver: Perspectives on Identification and Measurement

http://www.stahle.fi/National_Intellectual_Capital_as_an_Economic_Driver_200408_final.pdf

[online].Available:

Stiglitz J. (2009). American model is failed, Russian Newsweek, 16 (238), 37.

Sveiby K. E. (1997). The New Organizational Wealth; Managing and Measuring Knowledge-Based Assets, Berret-Koehler Publ, San Fransisco.

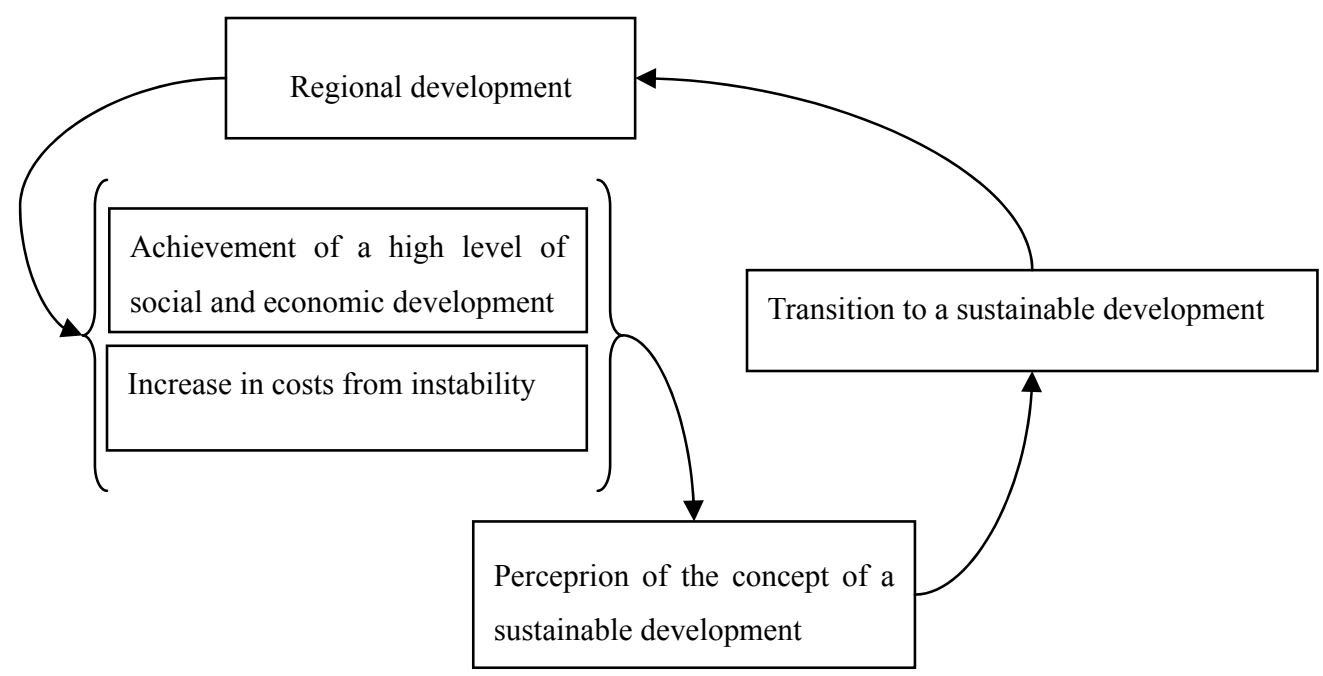

Figure 1. Movement to a sustainable development 


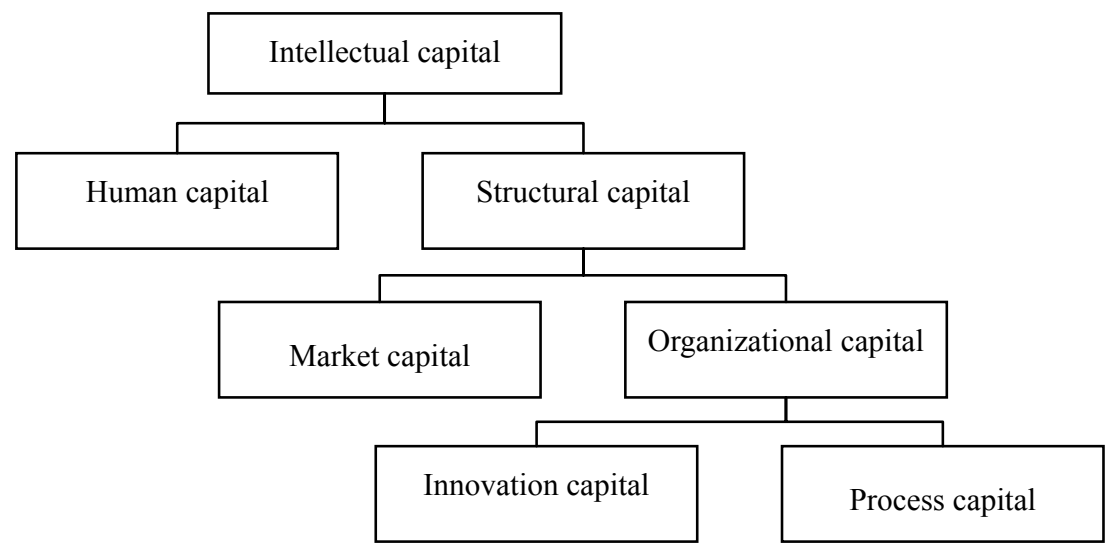

Figure 2. Intellectual capital model developed by Edvinsson and Malone

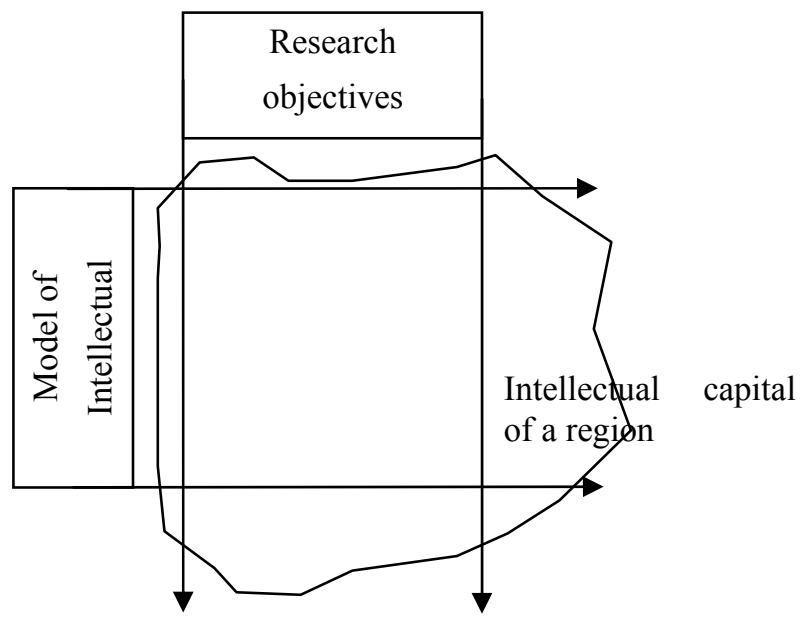

Figure 3. The mechanism of formation of sustainable development estimation model

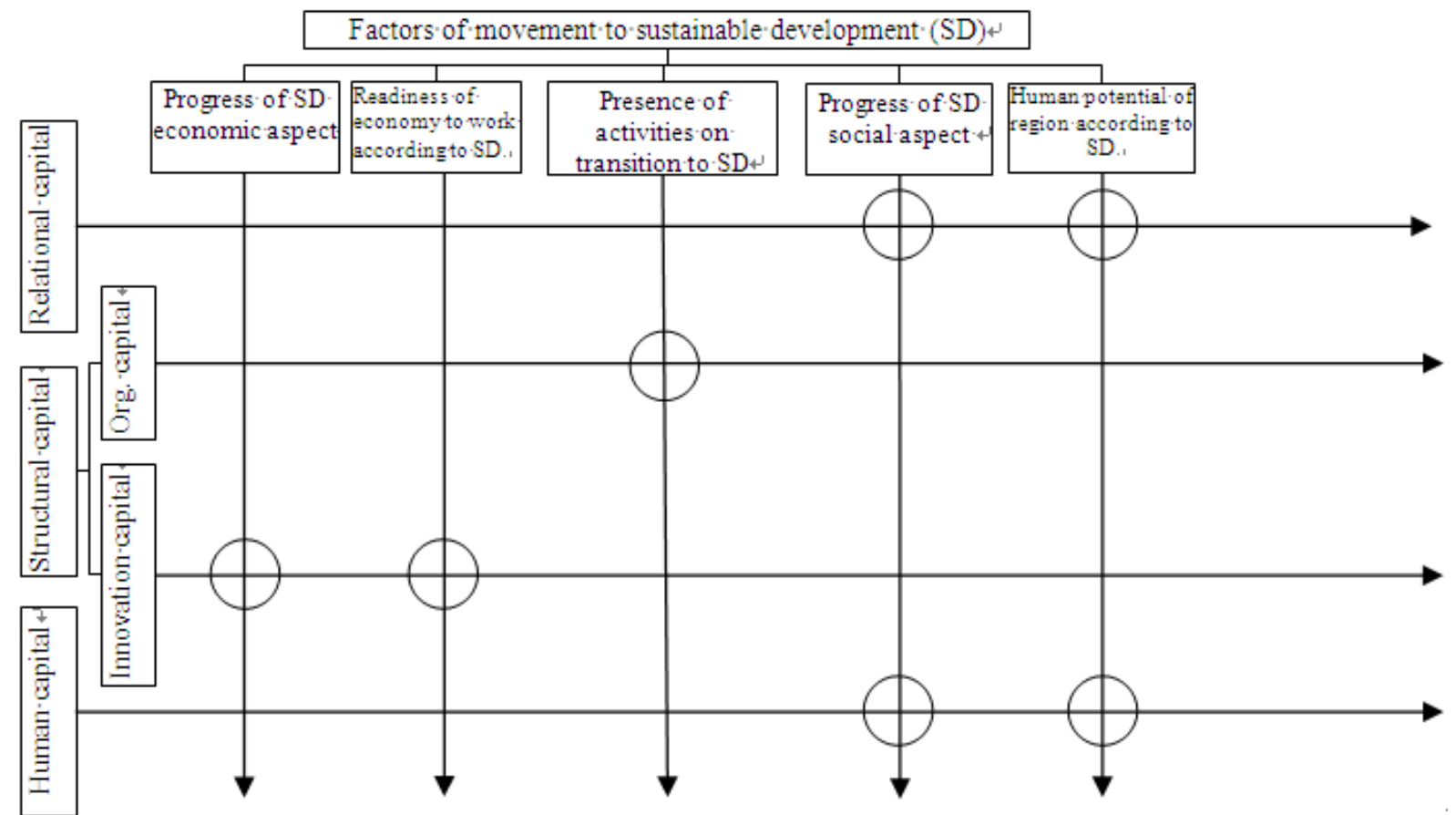

Figure 4. Elements of sustainable development estimation model 


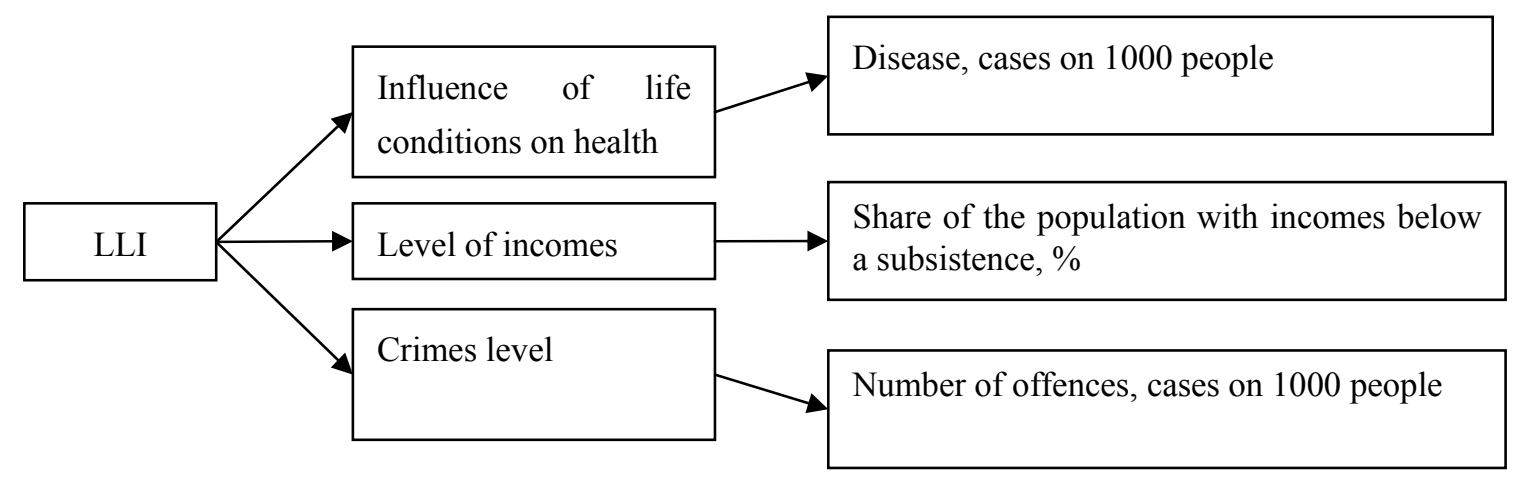

Figure 5. Possible structure of LLI

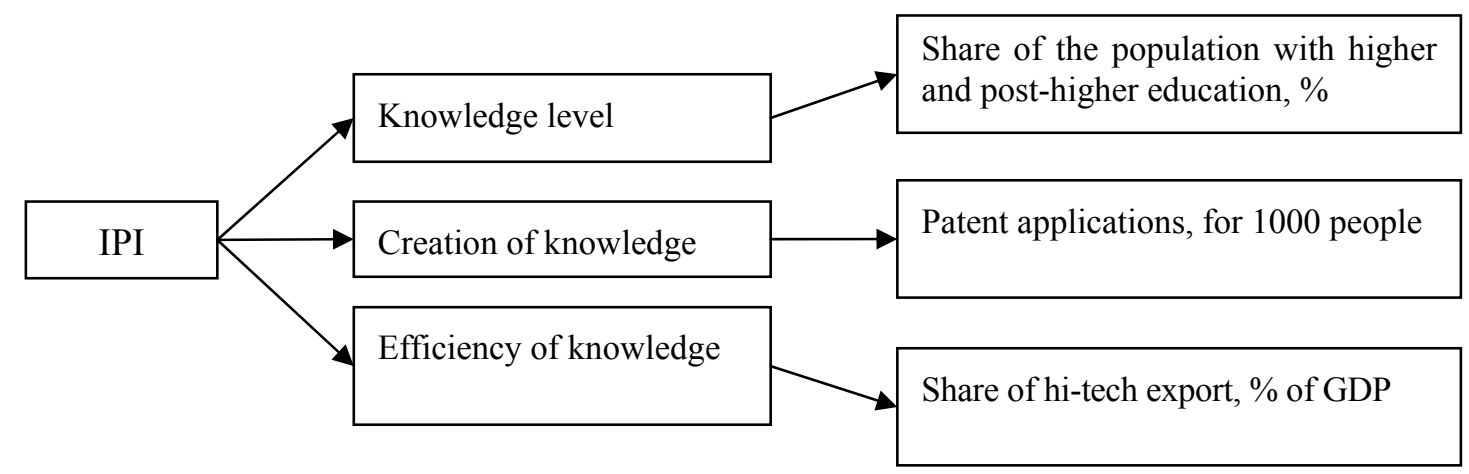

Figure 6. Possible structure of IPI

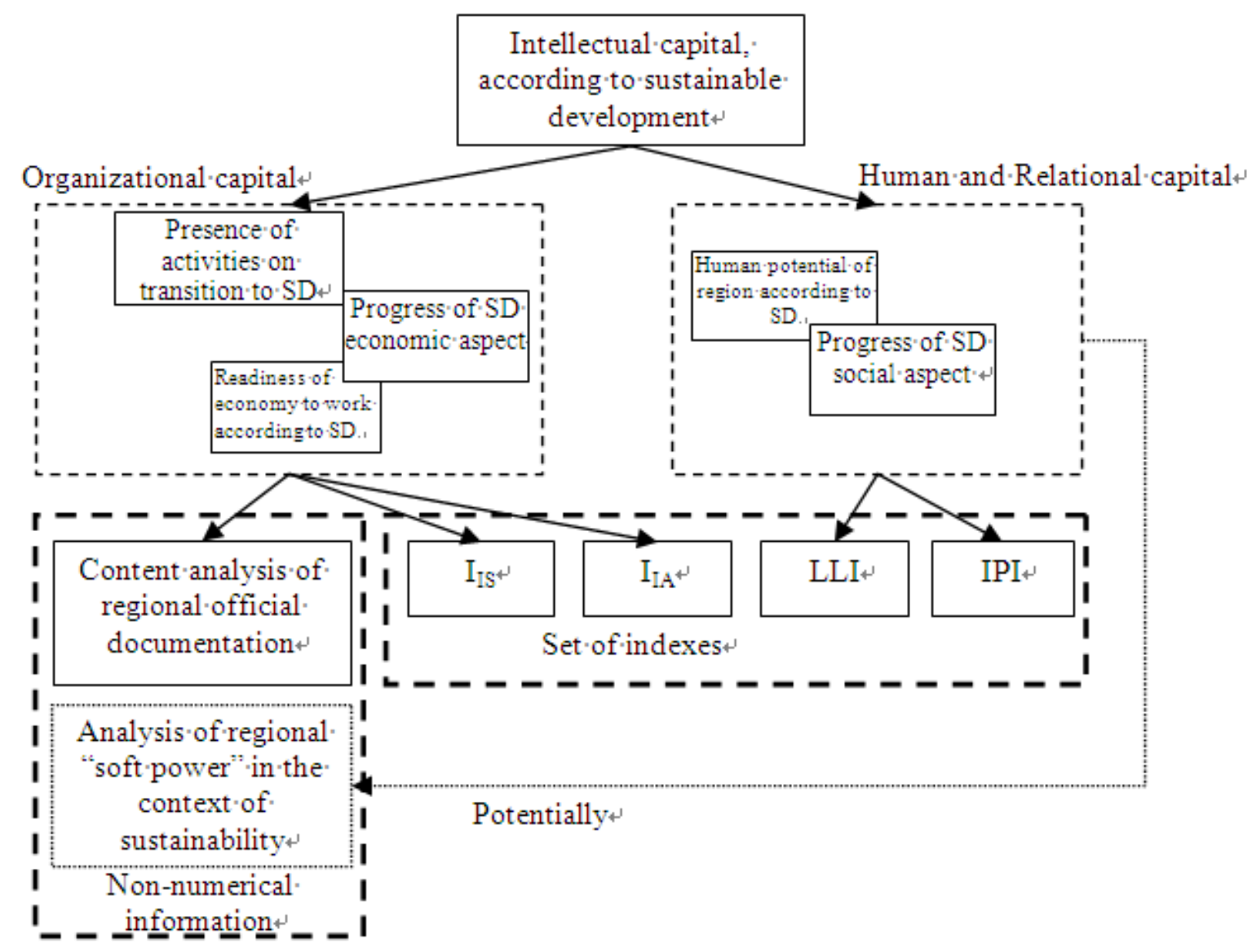

Figure 7. Sustainable development estimation model 